\title{
Study on Business Data Analysis Course Based on Business Scenario Requirement
}

\author{
He Junying \\ School of Economics and Management, Yunnan Open University, Yunnan Vocational \& Technical \\ college of National Defense Industry, Yunnan 650000, China \\ hejunying_edu@163.com
}

Keywords: e-commerce, data analysis, business scenario requirement

Abstract: With the advent of the big data era, e-commerce enterprises pay more and more attention on various kinds of data, and so the demand for data analysis talents has been increasing. At present, students of higher vocational colleges lack practical ability in business data analysis, and the school education is seriously disjointed from the enterprise demand. In this paper, the enterprise business scenario requirements are first analyzed. Then, according to the demand, the teaching of business data analysis course is studied. This paper makes a detailed analysis of the research process from three aspects such as curriculum design, curriculum implementation and curriculum assessment.

\section{Introduction}

With the development of data industries such as data acquisition, data storage, data mining and data analysis, enterprises need more data talents. At the China big data industry summit in May 2016, professor Wu weihong of Tsinghua university pointed out that:”In the next 3-5 years, China needs 1.8 million data talents, but currently only about 300,000 people, with a gap of 1.5 million" [1]. As data science matures, the power of data is emerging. The value of data to business is like the value of electronics to technology, and it is gradually becoming the reality of modern business [2].

At present, many higher vocational colleges and universities have offered business data analysis courses and even data analysis specialties. However, it is common that students lack practical skills and also Students lack the Key Competitiveness of business data analysis [3]. In view of this, this paper studies the teaching of business data analysis based on business scenario requirement. This research can improve the data analysis ability for student of E-commerce major.

\section{The Requirement of Enterprises for Data Analysis Capacity}

The demand of enterprises, especially e-commerce enterprises, is an important reference basis for cultivating students of higher vocational e-commerce major. It is necessary to deeply explore the demand of enterprises for data analysis capacity. Based on a survey of domestic e-commerce firms, it is found that there are three levels of enterprises' ability demands for data analysis positions. It is shown in the following table 1. 
Table 1 The Requirements of Enterprises

\begin{tabular}{|c|l|l|}
\hline level & \multicolumn{1}{|c|}{ Skill Points } & \multicolumn{1}{c|}{ The Specific Requirements } \\
\hline I & $\begin{array}{l}\text { Data analysis } \\
\text { tool }\end{array}$ & $\begin{array}{l}\text { using simple data analysis tools to summarize, clean, and repair } \\
\text { data }\end{array}$ \\
\hline II & $\begin{array}{l}\text { General methods } \\
\text { of data analysis }\end{array}$ & $\begin{array}{l}\text { using data analysis tools and common data analysis methods to } \\
\text { analyze the data }\end{array}$ \\
\hline III & $\begin{array}{l}\text { Business analysis } \\
\text { using data analysis tools and data analysis methods to analyze } \\
\text { professional data according to business requirement }\end{array}$ \\
\hline
\end{tabular}

\section{The Data Analysis Business Scenario}

\subsection{Original Data Sorting}

This is basic business case of the enterprise. According to the daily business data, the simple data analysis tools are used to summarize the data and form the original business data of the enterprise.

\subsection{Single Data Analysis}

Single data analysis is a simple data collation and analysis of enterprises' products, customers, orders, inventory and other business data. Product analysis can help the enterprise to improve product sales. Analyze product sales, channel, time and structure to optimize marketing strategy. Customer analysis can help enterprises enliven customer groups. It can explore customer value and avoid customer loss, to improve customer retention rate. Order analysis can help enterprises understand the basic order quantity, product price distribution, sales area distribution and customer purchase behavior. Inventory analysis can help enterprises reduce bad inventory. Analyze the dynamic sales of inventory, forecast the replenishment of goods and avoid the accumulation of inventory and the generation of bad inventory.

\subsection{Multiple Data Analysis}

Multiple data analysis is an enterprise analysis of market, competition or marketing effectiveness. Market analysis can help the enterprise take over the market, market the market, predict the market, and effectively adjust the market or brand strategy in time. The analysis of competitors can help enterprises win the competition war, grasp the market competition situation and the differences between products and markets, and optimize the decision-making of enterprises in the competition strategy. Analysis of marketing effects helps enterprises reduce marketing and advertising costs, fully understand marketing and advertising effects, adjust marketing and advertising strategies, and improve investment returns.

\subsection{Comprehensive Data Analysis}

Comprehensive and strongly correlated data analysis is the most difficult business scenario for the enterprise. This kind of business scenario is to analyze data for business decisions. The establishment of integrated data dashboard is a common business scenario for data monitoring and diagnosis. This not only requires data analysts to understand technology, but also requires them to have business operation. Through data analysis, enterprises can quickly find business problems and solve them as soon as possible. 


\section{The Business Data Analysis Course Based on Scenario Requirement}

\subsection{Curriculum Design}

According to the demand of enterprises for data analysis ability, higher vocational e-commerce major should focus on cultivating students' ability of using data analysis tools, application of data analysis methods and business analysis. This course is designed for application and follows the principle of "necessary and sufficient". The data analysis tool selects the simplest and most practical Excel software;

The data analysis method picks up the usual statistical analysis methods; the ability of business analysis relies on school-enterprise cooperative enterprises to provide practical posts and participate in project operation. The business analysis ability of an enterprise consists of four modules: acquisition of business data; reading and analysis of single data; multiple data analysis; production of operational data dashboard. It is shown in the following figure.

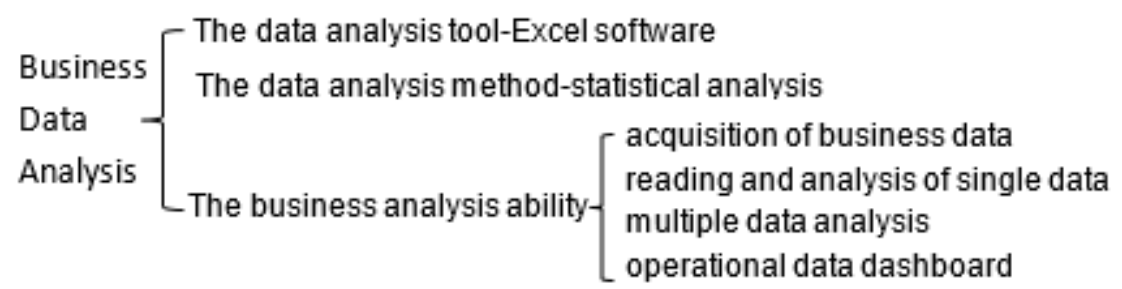

Figure 1 The Curriculum Design of Business Data Analysis

\subsection{Curriculum Implementation}

The course of business data analysis has two important parts: classroom learning and enterprise practice. Classroom learning is concentrated in class learning data analysis system of knowledge, the learning in class is given priority to, added the Internet learning auxiliary teaching form of teaching. It is emphasize that teachers' professional knowledge can be taught to student through interaction between teachers and students. After class, the abundant learning resources of the Internet are used to supplement the cutting-edge knowledge related to learning data analysis.

The enterprise practice is to focus on the training of students' enterprise business analysis capability. The main teaching method is to rely on the practical posts provided by the school-enterprise cooperation enterprise, so that students can get deeply involved in the daily operation of the enterprise, and get real access to all kinds of data of the enterprise. Under the guidance of the enterprise tutor, students can summarize and modify various data of enterprise operation. Students can improve their business analysis ability through practical training programs, which is that data analysis of the marketing campaign.

\subsection{Curriculum Assessment}

Multiple evaluation methods are adopted in the assessment design, including process evaluation and result evaluation, single evaluation and comprehensive evaluation, summative evaluation and developmental evaluation [4].

The curriculum assessment includes three assessment contents: process evaluation, training skill examination and finality assessment. Process evaluation is the evaluation of students' classroom performance, homework and time test, accounting for $20 \%$ of the comprehensive score; training skill examination mainly examine the completion of students' practical projects, accounting for $30 \%$ of the comprehensive scores, which are given by the enterprise tutor; The finality assessment is that 
before the end of the semester, the assessment questions are given by the teaching and research department, accounting for $50 \%$ of the comprehensive scores.

\section{Conclusions}

This paper mainly elaborates on the teaching research of business data analysis based on the business scenario demand of enterprises. Enterprise tutors participate in practical teaching, which can fully mobilize students' enthusiasm for learning. Taking objective facts as the evaluation standard, the curriculum pays attention to the cultivation of students' learning ability and practical ability. It can raise that data analysis business capability of higher vocational student.

\section{Acknowledgment}

This research is supported by 2017-2019 High Quality Vocational College Construction of Yunnan Vocational \& Technical college of National Defense Industry "E-commerce major construction "(ID: 2018-1-5)

\section{References}

[1] Liu chunyuan, Bai hao. Experts: China's data talent gap is about 1.5 million [EB/OL]. http://www.xinhuanet.com/legal/2016-05/31/c_129028181.htm.

[2] Shen fengchi. Research on professional setting of business data analysis and application in higher vocational colleges [J]. E-Commerce, 2016, (12): 74-75.

[3] Huang shaojie, Luo wei, Hou zhiping. Research on the mechanism of improving data analysis ability of e-commerce specialty based on project practice [J]. Industrial \& Science Tribune, 2017, 16(24): 250-251.

[4] Jia yan. Research on the blended teaching reform of statistical data analysis and processing based on post vocational ability [J]. HeBei Vocational Education, 2018, 2(2): 75-77. 